\title{
Atenção integral à saúde e diversidade sexual no Processo Transexualizador do SUS: avanços, impasses, desafios*
}

| 'Tatiana Lionço |

Resumo: A publicação da norma sobre o Processo Transexualizador no SUS, apesar de refletir importante conquista do segmento populacional de transexuais, denuncia a complexidade do avanço dos direitos sexuais no campo da Saúde Coletiva. O artigo tem por objetivo a consideração crítica dos avanços, impasses e desafios na instituição dessa política pública de saúde, discutindo a ambivalência no processo de construção da norma técnica. Resgata duas correntes paralelas de inserção do debate sobre saúde de transexuais no Ministério da Saúde: a judicialização e o compromisso com o programa de governo Brasil sem Homofobia. Sinaliza a qualidade parcial do avanço conquistado pela publicação da norma, já que estabeleceu, ao mesmo tempo em que afirmou o direito à saúde para transexuais, campos de exclusão para possíveis beneficiários das mesmas ações de saúde previstas, especificamente as travestis. A hipótese sustentada é a da incidência da heteronormatividade e do binarismo de gênero como fator limitador da democratização dessa política de saúde.

> Palavras-chave: transexualidade; homofobia; diversidade sexual; heteronormatividade; travestis.
${ }^{1}$ Doutora em Psicologia e pesquisadora da Anis (Instituto de Bioética, Direitos Humanos e Gênero), Brasília, DF.

Endereço eletrônico: t.lionco@anis.org.br. 
Por meio da Portaria GM n ${ }^{\circ}$. 1.707, de 18 de agosto de 2008 (BRASIL, 2008a), o Ministério da Saúde formalizou diretrizes técnicas e éticas para a atenção ao Processo Transexualizador no Sistema Único de Saúde (SUS). O Processo Transexualizador compreende um conjunto de estratégias de atenção à saúde implicadas no processo de transformação dos caracteres sexuais pelos quais passam indivíduos transexuais em determinado momento de suas vidas. Não se trata, portanto, do estabelecimento de diretrizes para a atenção integral no sentido estrito, mas daquelas açôes necessárias à garantia do direito à saúde circunscritas à passagem para a vivência social no gênero em desacordo com o sexo de nascimento.

Essa ressalva é importante por permitir explicitar que, por mais que a normatização desse processo tenha sido um ganho desse segmento populacional, não responde à questão da precariedade do acesso ao sistema de saúde quando se considera que a porta de entrada do mesmo deve ser prioritariamente a atenção básica, já que seria antagônico ao princípio da universalidade do SUS o estabelecimento de nichos diferenciados para a atenção a um determinado grupo social, em diferenciação ou discriminação em relação aos demais. Uma iniciativa importante para a promoção do acesso universal ao sistema de saúde, por exemplo, foi a introdução, na Carta dos Direitos dos Usuários da Saúde (BRASIL, 2006), do direito ao uso do nome social, seja nos serviços especializados já existentes que acolhem transexuais e travestis, seja em quaisquer outros serviços dispostos na rede de saúde pública.

A regulamentação do Processo Transexualizador - formalizada pela Portaria da Secretaria de Atenção à Saúde no 457, de 19 de agosto de 2008 (BRASIL, 2008b) -, permite afirmar que se trata de uma normatização que visa a resgatar os princípios da universalidade do acesso e integralidade na atenção, mas especificamente em relação às dimensões físicas e psicossociais implicadas no processo de transformação fenotípico e social característico à transexualidade, prioritariamente no contexto da atenção especializada. Envolve a habilitação de determinados hospitais universitários que já vinham prestando serviços de atenção a essa população específica, ${ }^{1}$ com previsão de destinação orçamentária para procedimentos médicocirúrgicos envolvidos na transgenitalização e demais alterações de caracteres sexuais, reiterando os critérios estipulados pelo Conselho Federal de Medicina ${ }^{2}$ para a sustentação da licitude da aplicabilidade dos procedimentos. A dimensão diferencial da norma brasileira é o estabelecimento de parâmetros éticos para a condução do 
processo de atenção à saúde, com ênfase na garantia da autonomia e no enfrentamento dos agravos decorrentes de processos discriminatórios.

Para as pessoas diretamente interessadas no acesso a esses procedimentos médicos, e também para os profissionais envolvidos em seu cuidado, a norma representa evidentemente uma importante conquista social e dá provas do potencial contra-hegemônico do SUS. Não se trata, no entanto, de um ganho incontornável, já que tramita atualmente Projeto de Decreto Legislativo para sustar os efeitos da Portaria GM no 1.707, que normatiza o Processo Transexualizador e viabiliza o custeio dos procedimentos pelo SUS. ${ }^{3}$ Vale lembrar também que a decisão do Tribunal Regional Federal do Rio Grande do Sul, ${ }^{4}$ de 14 de agosto de 2007, que decidia pelo custeio das cirurgias de transgenitalização em casos de transexualidade, foi julgada improcedente, em dezembro de 2007, pela então Ministra do Supremo Tribunal Federal (STF) Ellen Gracie 5 (ARÁN; Lionço, 2007), restando ainda a matéria inconclusa pela Justiça.

Este artigo tem como objetivo a consideração crítica dos avanços, impasses e desafios na instituição dessa política pública de saúde recentemente formalizada no Brasil. Pretende fortalecer a argumentação sobre sua pertinência, embora já sinalizando desafios a serem superados para o avanço dos direitos sexuais no contexto da saúde pública.

Dois parâmetros podem ser considerados fundamentais para a análise da normatização do Processo Transexualizador do SUS: (1) o reconhecimento do processo de construção da norma técnica e (2) a problematização da própria estratégia normativa sobre a sexualidade e as expressóes de gênero, a partir da consideração da heteronormatividade e da afirmação da diversidade sexual e de gênero.

O eixo estruturante de ambos os parâmetros de questionamento é a questão da justiça social e a consideração da violação de direitos humanos e sociais em função da sexualidade e das expressóes da masculinidade e da feminilidade. Ainda, remete para o necessário questionamento de valores morais hegemônicos que permeiam a própria busca pela justiça social de grupos sociais que sustentam em sua luta a afirmação da diversidade sexual como valor social a ser preservado diante do franco desprivilégio de status a que estão submetidos em função da sexualidade e das performances de gênero (FRASER, 2008; BUTLER, 2003). Isso significa que, ainda que o objeto deste artigo seja uma política publica imersa nas políticas de reconhecimento da diversidade sexual, a iniciativa não deixa de estar imersa nos processos de normatização da sexualidade e do gênero. 
A menção à diversidade sexual no contexto da discussão sobre uma política de saúde específica para o segmento de transexuais pode, a princípio, soar deslocada. No entanto, trata-se de uma estratégia argumentativa que visa a evidenciar os impasses no avanço, parcial, da garantia dos direitos sexuais no campo da Saúde Coletiva. Busca enfatizar como o processo de normatização, ao mesmo tempo em que gera parâmetros para a garantia de direitos, pode também se prestar a gerar novas demarcações de exclusão (BARSTED, 2008), como será explorado ao longo do presente artigo.

\section{Justiça social e diversidade sexual}

A justiça social é aqui compreendida na perspectiva da equidade, ou seja, pressupõe que a universalidade dos direitos humanos e sociais só pode ser assegurada mediante o reconhecimento e consideração das diferenças entre grupos sociais que se encontram em situação não apenas de distinção, mas também de desigualdade. Uma democracia liberal tem a equidade como princípio de justiça, por meio do reconhecimento de que as diferenças sociais, econômicas e morais não deveriam idealmente comprometer a garantia dos direitos, que são universais e aos quais não caberiam exclusões, mas que requerem estratégias diferenciadas para a garantia dos direitos em situações e circunstâncias distintas (RAWLS, 2002).

Uma democracia se caracteriza fundamentalmente pelo pluralismo, e ao mesmo tempo pela possibilidade de um consenso sobreposto entre diversas comunidades morais sobre os princípios e normas societárias (RAWLS, 2002). No Brasil, a Constituição de 1988 expressa o projeto democrático ao afirmar o pluralismo ou diversidade como valor social, bem como a universalidade dos direitos sociais.

A justiça social na perspectiva da equidade requer paridade participativa no espaço público e igualdade de oportunidades (FRASER, 2008; RAWLS, 2002). A paridade participativa no espaço público requer o reconhecimento e visibilidade de uma dada condição particular ou de grupo, sem que as diferenças comprometam a igualdade nas possibilidades de participação na razão pública. Não se trata apenas de assegurar liberdade e autonomia sobre as decisões individuais, mas também sobre as políticas públicas. Já igualdade de oportunidades requer não-discriminação. A igualdade é um parâmetro ético diretamente relacionado à universalidade dos direitos sociais. Afirma-se a igualdade como um ideal de justiça, mas não como exigência moral para as condutas e modos de vida. 
O SUS se estrutura em torno de princípios consonantes a esses preceitos de justiça social: afirma a universalidade do acesso aos serviços de saúde, com integralidade na atenção e participação social na formulação e implementação das políticas de saúde. A equidade, apesar de não ser um princípio expresso na Constituição Federal e na Lei Orgânica da saúde, é um conceito-chave para a promoção dos princípios da universalidade, integralidade e participação social (COSTA; LIONÇO, 2006).

A injúria é emblemática da iniquidade e demarcadora do campo da injustiça social: cerceia a ocupação do espaço público pela desqualificação do status social dos indivíduos, minando a igualdade de oportunidades. A vivência da homossexualidade, assim como a da expressão do gênero em descordo com o sexo biológico, é marcada pela injúria (ERIBON, 2008). "A injúria é um ato de linguagem - ou uma série repetida de atos de linguagem - pelo qual um lugar particular é atribuído no mundo àquele que dela é o destinatário" (ERIBON, 2008, p. 29). É pela noção de injúria que fica claro que a sexualidade e as expressões de gênero não são apenas matérias da vida privada, mas também da vida pública. A injúria, característica à discriminacão homofóbica, veicula a desqualificação do status social de determinados indivíduos, revelando uma dinâmica de poder hierarquizado entre aquele que pronuncia e sustenta a desvalorizacão, por um lado, e aquele que tem sua experiência de vida reduzida à significacão de desvalor, por outro. Não se trata, portanto, do estabelecimento da relação social na base no reconhecimento da alteridade, mas de um ato de linguagem que reduz o outro ao desmérito, por não ser igual àquele a quem está assegurada a normalidade, em função de padrões morais hegemônicos.

A Carta Constitucional explicita a universalidade dos direitos sociais, sem discriminação de qualquer espécie, apresentando a diversidade como valor social. Considerando ser a intimidade inviolável, a sexualidade não pode se restringir a padrões unívocos, denotando a própria pluralidade entre os cidadãos e grupos sociais, bem como a de suas formas de laço afetivo. O conceito de diversidade sexual apresenta aqui uma função central e estratégica para a proteção dos direitos sociais de pessoas que encontram na orientação sexual e na expressão de gênero fatores de violação de seus direitos, tendo como fatores de prejuízo social a heteronormatividade e a naturalização do binarismo de gênero, sócio-historicamente construídos. Ainda, a noção de diversidade sexual visa a explicitar o potencial de 
variação das orientações sexuais e expressões de gênero, por meio da ênfase na ideia de pluralismo, servindo para problematizar também as afirmaçōes identitárias que carregam a marca da essencialização. ${ }^{6}$

A heterossexualidade, associada ao binarismo essencialista do gênero, configura a matriz de inteligibilidade a partir da qual a diversidade sexual ganha sentido. Isso quer dizer que é a partir da heterossexualidade, e da bipartição estanque entre a masculinidade e a feminilidade, tomadas como parâmetro da normalidade, que toda e qualquer expressão da sexualidade e do gênero é valorada. Configura uma norma, um princípio ordenador segundo o qual a pluralidade das experiências sexuais e de gênero é significada (BUTLER, 2003; ARÁN, 2006). A afirmação da diversidade sexual como valor é um contraponto à heteronormatividade e à dinâmica homofóbica, que veicula a desqualificação do status social de certos indivíduos.

A heterossexualidade e a adequação aos estereótipos de gênero ganham a força da compulsoriedade. Butler (2003) afirma que o alinhamento entre sexo-gênerodesejo é a estrutura fundante da heteronormatividade ou heterossexualidade compulsória. Um corpo biologicamente sexuado nascido teria como destino unívoco a expressão do gênero que lhe seria correspondente, que por sua vez determinaria a característica do objeto de amor ou do erotismo: o outro sexo ou sexo oposto.

A heteronormatividade e o binarismo de gênero se formalizam em grande parte no discurso médico, que desde o século XIX se ocupou em normatizar as condutas sexuais e as expressões da masculinidade e da feminilidade em parâmetros de saúde/ normalidade ou de doença/anormalidade (ARÁN, 2006).

A heteronormatividade e o binarismo de gênero repercutem em práticas discriminatórias, como é o caso da homofobia, uma prática de discriminação baseada na suposição da normalidade da heterossexualidade e dos estereótipos de gênero. Homofobia é um conceito recente que permite apreender a permanência da defesa ferrenha ao patriarcado, o que leva a reconhecer a estreita associação da homofobia ao sexismo: atribui desprivilégio de status social ao feminino (FRASER, 2008), sem, no entanto, restringir o rebaixamento da feminilidade à condição biológica do sexo. O sexismo e a homofobia emergem como consequência do regime binário da sexualidade (BORRILLO, 2000), essencializando a feminilidade e a masculinidade em identidades mutuamente excludentes e cerceadoras das possibilidades de derivação passível da apropriação pessoal, social, cultural e histórica do feminino e do masculino, por pessoas de ambos os sexos. 
A emergência da homofobia como conceito se fundamentou no giro epistemológico que deslocou o foco da essencialização de identidades ou categorização das condutas sexuais, característica ao discurso médico psicopatológico, para a consideração crítica dos discursos excludentes e de desprivilégio do status social de pessoas e grupos em função de suas práticas sexuais e formas de expressar a feminilidade e a masculinidade (BORRILLO, 2000).

\section{Construção e formalização da norma sobre o Processo Transexualizador no SUS}

O processo de construção da norma denominada Processo Transexualizador no SUS é marcado pela ambivalência. Duas forças concomitantes foram fundamentais para a viabilização do seu processo de construção e formulação, a saber, a judicialização da demanda pela regulamentação e financiamento do procedimento de transgenitalização no SUS, e a abertura institucional do Ministério da Saúde para a participação social na formulação dessa política pública.

Data de 2001 a Ação do Ministério Público Federal pela inclusão, na tabela de procedimentos do SUS, dos procedimentos de transgenitalização mencionados na Resolução no 1.842/1997 do Conselho Federal de Medicina. Note-se que a demanda era pelo custeio dos procedimentos médico-cirúrgicos no sistema de saúde público, sustentada na argumentação de que os procedimentos médicos implicados na transgenitalização já estavam incorporados na tabela do SUS, embora não acessíveis a pessoas transexuais. Do ponto de vista jurídico, essa restrição sustentaria a discriminação baseada no sexo, dado que viabilizaria benefícios biomédicos já disponíveis a pessoas que não apresentassem incongruência entre o sexo biológico e o gênero (casos de lesão ou má-formação genital), e dada a compreensão do caráter de beneficência das cirurgias em casos de transexualismo. Nesse contexto, o transexualismo é afirmado como uma doença que requer tratamento médico, sendo a argumentação sustentada no discurso médico, que apresenta a cirurgia reparadora como solução terapêutica.

Provavelmente a revogação dessa primeira Resolução do Conselho Federal de Medicina, pela Resolução no 1.652/2002, ainda vigente, esteve imersa nesse contexto de judicialização da demanda pelo custeio da transgenitalização. A mudança entre as resoluções mencionadas foi a da retirada, na segunda resolução, do caráter experimental do procedimento de neocolpovulvoplastia 
(transgenitalização de homem para mulher), sendo um dos impedimentos já alegados pelo Ministério da Saúde para responder à demanda do Ministério Público Federal justamente o caráter experimental da cirurgia, dado que o SUS não incorpora procedimentos cuja eficácia terapêutica não seja atestada pela comunidade médicocientífica. Dada a permanência do caráter experimental dos procedimentos de neofaloplastia e metoidioplastia (transgenitalização de mulher para homem), a norma publicada pelo Ministério da Saúde restringe a regulamentação e financiamento do Processo Transexualizador a mulheres transexuais (homem para mulher), ou o que mais recentemente vem sendo identificado como mulheres que vivenciam a transexualidade. ${ }^{7}$

O Ministério da Saúde, em 2004, chegou a publicar a Portaria no 1.397, posteriormente revogada, que instituía Grupo de Trabalho para discussão da inclusão dos procedimentos de transgenitalização na tabela do SUS. A composição desse grupo, no entanto, apresentava-se incompleta e, embora tenha sido revogada, algumas reunióes com base nos trabalhos previstos na mesma efetivamente ocorreram entre os anos 2006 e 2007, posteriormente à participação do gestor responsável pela Coordenação de Média e Alta Complexidade da Secretaria de Atenção à Saúde na I Jornada Nacional sobre Transexualidade e Saúde, realizada em 2005 pelo Instituto de Medicina Social da UERJ. Esse evento desempenhou importante função como marco inaugural de coletivização da discussão entre movimento social, trabalhadores, pesquisadores e gestores num mesmo espaço de formulação de diretrizes para a atenção à saúde de transexuais.

Paralelamente à judicialização da demanda relativa à saúde de transexuais, em 2004 foi instituído o Comitê Técnico Saúde da População GLTB (Gays, Lésbicas, Transgêneros e Bissexuais) pela Portaria GM no 2.227. ${ }^{8}$ Para além da institucionalização desse comitê técnico, como resposta do setor saúde ao Programa de Governo Brasil sem Homofobia, é importante destacar que o Ministério Público Federal permaneceu interpelando o Ministério da Saúde, que por diversas vezes teve que prestar contas dos encaminhamentos dados à demanda formalizada em 2001.

De fato a instituição desse comitê técnico foi fundamental para a abertura institucional para a participação social do movimento LGBT na formulação de políticas e estratégias afeitas a essa população. A partir de fórum realizado durante o XII Encontro Nacional de Gays, Lésbicas, Bissexuais, Travestis e Transexuais (EBGLT), em 2005 em Brasília, decidiu-se pela abertura de assento específico 
para representação do segmento de transexuais, que até então disputava com as travestis espaço de interlocução com o governo sob o conceito mais abrangente de transgêneros. A fundação do Coletivo Nacional de Transexuais, ocorrida durante o I Encontro Nacional de Transexuais - evento que transcorreu paralelamente ao XII EBGLT -, reforçou a demanda por visibilidade e por espaço de representação próprio ao segmento. O Ministério da Saúde, por meio do ComitêTécnico Saúde da População GLTB, foi o primeiro setor governamental a reconhecer a organização social de transexuais e a abrir formalmente espaço de participação social desse segmento na formulação de políticas públicas. O Comitê realizou, em fevereiro de 2006, reunião denominada Processo Transexualizador no SUS, marco da incorporação dessa terminologia na discussão sobre saúde de transexuais, que até então estivera restrita à lógica do custeio dos procedimentos médico-cirúrgicos implicados na transgenitalização.

A inclusão da perspectiva de processo foi estrategicamente adotada para superar a restrição da compreensão da atenção à saúde de transexuais, centrada até então no evento cirúrgico. Ainda, as discussões nesta reunião específica do Comitê Técnico, que contou com a participação de lideranças do movimento social (tanto de mulheres transexuais quanto de homens transexuais) e de profissionais e pesquisadores que atuam na atenção à saúde dessa população, priorizaram a problematização do caráter psicopatológico da transexualidade e evidenciaram a própria patologização como fator de sofrimento e agravo à saúde, questionando a centralidade das medidas médico-cirúrgicas na atenção a transexuais. A reunião sobre o Processo Transexualizador no SUS, portanto, enfatizou a necessária despatologização da transexualidade como estratégia de promoção da saúde, e afirmou a pluralidade na transexualidade, considerando que a autonomia da pessoa transexual na tomada de decisão sobre as medidas necessárias a uma melhor qualidade de vida seria fundamental para que a atenção à saúde não dispusesse novos mecanismos de controle e normatização sobre as condutas e modos de vida e de subjetivação. As cirurgias, portanto, passaram a ser compreendidas como parte ou não do Processo Transexualizador, e a discussão superou o viés medicalizador e correcional para o foco na garantia do direito à saúde integral.

Essa nova perspectiva na discussão sobre atenção à saúde de transexuais ganhou força no Seminário Nacional Saúde da População GLBT na Construção do SUS, realizado pela Secretaria de Gestão Estratégica e Participativa do Ministério da 
Saúde em 2007, bem como na Conferência Nacional LGBT, realizada em 2008 sob a coordenação da Secretaria Especial dos Direitos Humanos, da Presidência da República. Concomitantemente a esses importantes marcos políticos de fortalecimento da vocalização desses grupos sociais sobre suas necessidades e demandas em saúde, reuniōes impulsionadas pela interpelação do Ministério Público Federal foram realizadas no Ministério da Saúde, mas já qualificadas por este debate coletivizado nos mencionados eventos.

Nesse sentido, a construção da norma Processo Transexualizador no SUS reflete a garantia de participação social, que permitiu o alargamento da perspectiva da atenção à saúde para além do viés médico-biológico e psiquiátrico, resgatando os princípios do SUS. Por outro lado, o fator impulsionador da retomada das discussōes e da efetiva publicação da portaria foi a reincidência das interpelações do Ministério Público ao Ministério da Saúde, o que denuncia que a judicialização da saúde nesse caso foi necessária diante de uma relativa omissão do Ministério da Saúde a responder à demanda de custeio das cirurgias, que, paradoxalmente, desde sua legalização, em 1997, foram determinadas para serem executadas justamente no SUS (ARÁN; MURTA; LIONÇO, 2008; ARÁN; LIONÇO, 2007).

\section{Normatizações: avanços e impasses dos direitos sexuais}

A retirada do termo homossexualismo do Manual Diagnóstico de Transtornos Mentais da Associação Psiquiátrica Americana, na década de 1980, que se desdobrou, na década de 1990, na retirada do mesmo termo da Classificação Estatística Internacional de Doenças e Problemas Relacionados à Saúde da Organização Mundial da Saúde (CID/OMS), se sustentou na afirmação de que a homossexualidade não seria patológica. Essa mudança significativa na compreensão da homossexualidade acarretou em resoluçôes de órgãos reguladores de categorias profissionais da área da saúde no Brasil.

O Conselho Federal de Psicologia (1999), através da Resolução no 001/99, estabelece normas de atuação para psicólogos em relação à questão da orientação sexual, enfatizando que devem contribuir com seu conhecimento para reflexóes críticas sobre os preconceitos e primar pelo combate à discriminação e estigma contra aqueles que apresentam comportamentos ou práticas homossexuais, não devendo esses profissionais exercer quaisquer ações que favoreçam a patologização dessas pessoas, sequer adotando açôes coercitivas que tendam a orientar 
homossexuais a tratamentos não solicitados. Aos psicólogos está vetado, a partir dessa resolução, tratamento e cura das homossexualidades.

O Conselho Federal de Serviço Social (2006), por sua vez, através da Resolução no 489/2006, estabelece normas vetando condutas discriminatórias ou preconceituosas, por orientação sexual, no exercício profissional do assistente social, resguardando ao sujeito o direito à singularidade e à diferença subjetiva. Infelizmente, os conselhos de classe profissionais se omitem em relação à necessidade de despatologização dos modos de ser transexuais e travestis, restando a esses indivíduos a nosologia médico-psiquiátrica como referencial norteador do exercício profissional não apenas de médicos, mas também com reverberações sobre a atuação de psicólogos e outros profissionais do campo da saúde.

Apesar da relativa proteção normativa concedida a gays, lésbicas e bissexuais por meio das resoluções dos conselhos de psicologia e de serviço social, a condição subjetiva de transexuais e travestis é considerada patológica, constando atualmente nos compêndios nosográficos médicos. Para Russo (2004), a medicina psiquiátrica posterior à década de 1980 vem contribuindo para a caracterização psicopatológica das manifestações da sexualidade e do gênero. Para a autora, o lançamento da terceira versão do Manual de Diagnóstico e Estatística de Distúrbios Mentais da Associação Psiquiátrica Americana (DSM III) elevou de modo significativo os transtornos/desvios relacionados à sexualidade e ao gênero, apesar da retirada do termo homossexualismo do manual.

Montoya (2006) também chama a atenção para o estabelecimento social de prescrições morais no campo da sexualidade humana, demandando reflexão sobre os processos de domesticação e normatização operados no campo da saúde por meio da patologização e reparação das experiências sexuais. Para Montoya (2006), as terapias reparativas ou correcionais, que tomam como objeto a sexualidade suposta como patológica, se sustentam na visão da psiquiatria como protetora da normalidade social e sexual. O saber médico psiquiátrico justifica as correçōes anatômicas, seja no argumento de anormalidade na conformação dos corpos (no caso de hermafroditismo, por exemplo), seja na dimensão do transtorno psíquico (no caso de transexuais, para os quais o que se supõe um "erro" no corpo deve ser corrigido).

A CID 10 (OMS) faz referência a transtornos de identidade sexual, que inclui o transexualismo como um desejo persistente de viver e ser reconhecido como um membro do sexo oposto, implicando um desconforto em relação ao sexo anatômico 
e busca de tratamentos hormonais e cirúrgicos, visando à adequação do corpo tanto quanto possível ao sexo preferido. Destaca-se aqui a afirmação de um parâmetro diagnóstico sustentado na própria oferta médica de tratamento para o que propõe como patologia. Dentro dessa mesma categoria, consta o travestismo bivalente, que implica o uso de vestimentas do sexo oposto durante uma parte da existência, de modo a satisfazer a experiência temporária de pertencer ao sexo oposto, mas sem desejo de alteração sexual mais permanente ou de uma transformação cirúrgica. O travestismo também está contemplado na categoria de parafilias, na CID 10, sob a denominação travestismo fetichista. Nessa segunda vertente, o travestismo é descrito como o hábito de vestir roupas do sexo oposto com o objetivo de obter excitação sexual e de criar a aparência de pessoa do sexo oposto, e está enquadrado como parafilia, termo contemporâneo para a perversão, junto a outras práticas e expressões da sexualidade associadas ao desvio de conduta, como, por exemplo, a pedofilia e o exibicionismo.

A definição de transexualismo desconsidera a pluralidade na transexualidade, estabelecendo como critério diagnóstico o desejo pela correção ou adequação da genitália à experiência do gênero. Em relação às definições de travestismo, ambas não contemplam o que estudos etnográficos vêm acumulando como descrição do modo de vida das travestis brasileiras, que buscam alterações permanentes nos caracteres sexuais secundários e vivem permanentemente o gênero feminino, apesar de não sentirem necessidade de corrigir a genitália cirurgicamente. Ser travesti seria investir permanentemente na construção de um corpo a ser reconhecido pelo outro como um corpo feminino. Diferentemente das transexuais, no entanto, as travestis não afirmam uma identidade feminina estrita, mas ostentam a androginia (OLIVEIRA, 1994; BENEDETTI, 2005; PELÚCIO, 2005; SILVA, 2007). Podese afirmar que transexuais e travestis são sujeitos que se constituem subjetivamente como indivíduos pertencentes a um gênero que não corresponde linearmente ao sexo de nascimento, sendo a diferença fundamental o fato de as travestis sustentarem uma ambiguidade ou duplicidade sexual na própria afirmação identitária.

Os avanços nas tecnologias biomédicas permitem atualmente a alteração dos caracteres sexuais secundários mediante hormonioterapias. Da mesma forma, procedimentos de alteração plástica e funcional na genitália, inicialmente aplicados a casos de ambiguidade ou lesão grave no órgão genital, são no momento estendidos a pessoas que não apresentam disfunções orgânicas que justifiquem essas medidas 
reparadoras, desde a inclusão da psicopatologia transexualismo nos compêndios nosográficos, e desde a consensual compreensão do caráter terapêutico ou de beneficência do procedimento de transgenitalização nesses casos.

Apesar de viverem experiências bastante próximas no sentido de buscar a transformação corporal permanente e irreversível dos caracteres sexuais secundários, travestis e transexuais encontram no diagnóstico diferencial um grande divisor de águas. A resolução do Conselho Federal de Medicina condiciona a aplicabilidade dos procedimentos médicos de alteração dos caracteres sexuais ao diagnóstico de transexualismo, tanto em relação à transgenitalização quanto à hormonioterapia. As travestis, portanto, permanecem excluídas da atenção à saúde e relegadas à automedicação ou à ação das bombadeiras - travestis que injetam silicone industrial para a modelagem dos corpos de outras travestis (BENEDETTI, 2005; PELÚCIO, 2005).

A hipótese aqui sustentada é a de que a regulamentação da aplicabilidade dos procedimentos médico-cirúrgicos sobre caracteres sexuais é restrita a casos de transexualismo porque se compreende, mediante a reparação cirúrgica, que uma certa normalidade poderia ser restituída. Como as travestis não demandam essa correção, reafirmando a insuficiência da lógica binária em dar conta das experiências subjetivas de posicionamento diante da diferença sexual, são excluídas do acesso aos serviços e aos recursos médicos em seus processos de transformação corporais, não dispondo de iguais oportunidades no acesso aos serviços e tecnologias disponíveis no campo médico.

Do ponto de vista médico, a afirmação do sentimento de pertencimento a um determinado gênero - masculino ou feminino - em desacordo com a atribuição do sexo de nascimento, encontra, como medida terapêutica, a readequação cirúrgica da genitália para corresponder à identidade de gênero, compreendida como estruturante e não passível de alteração por tratamentos psíquicos. A cirurgia seria, portanto, a correção ou o tratamento reparador para o transtorno identitário apresentado na situação patológica ou anormal.

Bento (2006) esclarece que no processo de avaliação de candidatos transexuais às cirurgias de transgenitalização se operam mecanismos de poder e de normatização das condutas. O dispositivo da transexualidade firmaria rígidas normas de conduta a esses indivíduos, destinados a provarem ser verdadeiros transexuais, ou seja, aproximando-se o máximo possível a uma mulher ou a um homem considerados 
normais, correspondendo caricatamente aos estereótipos de gênero vigentes, bem como adequando-se à norma heterossexual.

No caso de transexuais e travestis, o poder médico impõe restrições normativas e interdições para o acesso aos procedimentos que incidem sobre transformações corporais de caracteres sexuais, intermediando de forma reguladora o acesso aos bens e avanços biotecnológicos. Como afirma Ventura (2007), o poder médico não apenas regula o acesso aos recursos de saúde disponíveis para a superação do desconforto em relação ao próprio corpo e do desejo de transformação dos caracteres sexuais. O poder médico impede o acesso a esses recursos. Está impedido o acesso a esses recursos biomédicos àqueles indivíduos que não aderem integralmente à proposta terapêutica regulamentada, ou àqueles que não desejam explicitamente a recuperação de um estado similar ao considerado normal, na perspectiva do alinhamento linear entre sexo-gênero-desejo. Para a autora, o que está sendo impedido não é apenas o acesso a um procedimento cirúrgico ou de redução de danos pelo uso de hormônios. Está sendo negado o acesso às condiçôes necessárias para a livre expressão da personalidade.

É necessário reconhecer que transexuais e travestis vivenciam situações de extrema vulnerabilidade social, e que os agravos decorrentes das precárias soluções encontradas para lidar com o sofrimento relativo ao estranhamento em relação a seus corpos biológicos ou de nascimento dizem respeito, fundamentalmente, à omissão ou restrição da ajuda médica atualmente possível em termos biotecnocientíficos.

Já se chamou a atenção, tanto por parte da academia (ARÁN; MURTA; LIONÇO, 2008; ARÁN; MURTA; ZAIDHAFT, 2008; MURTA, 2007) como por parte do movimento social de transexuais, para a condição diagnóstica como fator viabilizador ou impeditivo do acesso aos serviços de saúde. Muito se discutiu sobre a pertinência ou não da afirmação do caráter psicopatológico da transexualidade. As reflexões de Butler (2006) condensam o debate brasileiro: se por um lado a psiquiatrização da transexualidade instrumenaliza o acesso aos serviços de saúde, por outro engendra novos sofrimentos por meio do estigma associado ao diagnóstico psiquiátrico. Esse impasse não encontra perspectiva de breve solução, embora seja urgente afirmar a heterogeneidade entre as pessoas que buscam os serviços de saúde para acompanhamento de seus processos de transformação corporais, e a precariedade do discurso médico psiquiátrico para alcançar essa diversidade. $\mathrm{O}$ condicionamento do acesso à atenção à saude ao diagnóstico demarca 
um campo restritivo e artificial, onde impera a lógica instrumental e avaliativa, senão correctional e punitiva.

A Bioética emerge, nesse contexto, como referencial privilegiado para a consideração da justiça social no contexto da diversidade sexual. A Bioética, enquanto campo multidisciplinar, e ao associar as práticas de assistência à saúde ao direito, é uma importante ferramenta ético-política para o questionamento de processos normatizadores que perpassam a atenção à saúde. Permite considerar criticamente práticas de assistência (ou mesmo a desassistência) sustentadas em preceitos morais que comprometem a universalidade do direito à saúde (LIONÇO, 2008).

\section{Políticas de reconhecimento e a essencialização das identidades em questão: o Processo Transexualizar no SUS como conquista parcial}

A construção de políticas públicas pressupõe a enunciação de identidades, para conferir visibilidade a grupos em situação de invisibilidade e exclusão do espaço público. As políticas de reconhecimento, no entanto, não necessariamente precisam se sustentar nas demandas e discursos identitários, que remetem à autoafirmação e à essencialização, mas ao recurso de evidenciar o desprivilégio do status social, ou as normas diante das quais sujeitos e grupos estão excluídos dos benefícios estatais.

Fraser (2008) propõe romper com o modelo padrão do reconhecimento que se sustenta na ideia de identidade, já que o não-reconhecimento pela identidade prioriza a estrutura psíquica em detrimento das instituições sociais e do laço social, mascarando a heterogeneidade interna aos grupos. $\mathrm{O}$ não-reconhecimento não é necessariamente a depreciação de uma identidade particular ou de um grupo, mas a subordinação social, a privação de participar como igual na vida social. $\mathrm{O}$ nãoreconhecimento emerge quando as instituições estruturam a interação de acordo com normas culturais que impedem a paridade de participação.

Além da problemática essencialização das supostas identidades transexual e travesti, categorizadas em diagnósticos médico-psiquiátricos insuficientes para o reconhecimento da pluralidade característica à vivência desses segmentos da população, vale notar que o avanço na consolidação do diálogo dos movimentos sociais com o Ministério da Saúde vem revelando uma outra face essencialista: a demanda pelo reconhecimento identitário. Mulheres transexuais requerem a inserção de suas reivindicações na Política Nacional de Atenção Integral à Saúde 
da Mulher, recusando qualquer menção a suas necessidades na Política Nacional de Saúde do Homem. Essa demanda identitária vem responder à reivindicação pelo reconhecimento social da identidade de gênero, mas é uma estratégia política insuficiente para alcançar a complexidade de saúde dessa população.

O ideal seriam iniciativas transversais entre diferentes políticas de saúde, a fim de otimizar a implementação de ações em saúde já desencadeadas no SUS de acordo com as especificidades de transexuais, não apenas entre os recortes de gênero, como nas políticas já mencionadas, mas incluindo também a questão da saúde no sistema penitenciário, do idoso, do adolescente e jovem, entre outras. A demanda identitária vem responder a um anseio por reconhecimento, em detrimento da complexificação e qualificação das estratégias e ações em saúde. Durante a apresentação da Política Nacional de Saúde do Homem no Conselho Nacional de Saúde, no fim de 2008, o segmento de travestis também se manifestou contrariamente à inserção de suas especificidades nesse documento, revelando que a demanda identitária pode comprometer iniciativas inclusivas em curso.

Ainda que travestis permaneçam excluídas do processo de atenção à saúde na norma Processo Transexualizador, é inegável que a publicação da portaria representa um avanço na consolidação dos direitos sexuais. A ênfase na autonomia da pessoa transexual na tomada de decisão sobre as estratégias médico-cirúrgicas necessárias à melhoria da qualidade de vida é uma diretriz fundamental para que a atenção à saúde de transexuais não se restrinja a novos mecanismos de poder e controle sobre os corpor e condutas sexuais das pessoas. Da mesma forma, a ênfase no processo de superação dos agravos decorrentes dos processos discriminatórios, sustentado na diretriz da atuação multiprofissional e do cuidado sobre os laços sociais e da inserção social, é um ganho fundamental dessa norma técnica proposta pelo Ministério da Saúde.

A desessencialização das identidades das ditas minorias sexuais é fundamental para a afirmação da sexualidade como direito humano e para a desconstrução de processos normatizadores sobre as condutas sexuais. A recente norma sobre o Processo Transexualizador no SUS é um exemplo interessante de como o avanço na consolidação dos direitos sexuais é marcado por ambivalências. Permite avaliar que os avanços nesse campo se operam processualmente, estabelecendo marcos normativos que se sustentam, por sua vez, nos referenciais normativos e discursos formais já disponíveis.

A heteronormatividade e a essencialização do binarismo de gênero são fatores 
cerceadores do avanço na consolidação da democratização dos direitos sexuais (RIOS, 2007). A busca pela democratização dos direitos sexuais deve levar em consideração que a heteronormatividade e a manutenção dos estereótipos de gênero são contrárias à afirmação da diversidade sexual como valor social. A justiça social requer a renúncia a toda forma de readequação das condutas sexuais e expressões de gênero a esse parâmetro excludente e ordenador de hierarquias de valor para o status dos indivíduos enquanto legítimos ou não para a participação no espaço público, o que implica, no campo da saúde, partilhar das decisões e ter igualdade de oportunidades no acesso aos bens e serviços.

Por outro lado, a restrição das demandas em saúde à lógica identitária, ao invés de contribuir para a desconstrução da essencialização do binarismo de gênero e da norma heterossexual, acaba por reforçar esses discursos normativos por meio da reiteração das categorias homem e mulher. A recusa em considerar as especificidades em saúde relativas ao sexo de nascimento cristaliza a discussão, cerceando as possibilidades de reconhecimento das variaçôes sociais, subjetivas e biológicas do ser homem ou mulher, que exemplarmente a transexualidade e a travestilidade impõem à elaboração do pensamento crítico.

\section{Referências}

ARÁN, M. A transexualidade e a gramática normativa do sistema sexo-gênero. Ágora: Estudos em Teoria Psicanalítica, v. 9, n. 1, p. 49-63, 2006.

ARÁN, M.; LIONÇO, T. Mudança de sexo: uma questão de justiça para a saúde. Série Anis: Brasília, n. 53, 2007, p. 1-3. Disponível em: http://www.anis.org.br/serie/ visualizar_serie.cfm?IdSerie=67. Acesso em: set. 2008.

ARÁN, M.; MURTA, D.; LIONÇO, T. Transexualidade e saúde pública no Brasil. Ciência e Saúde Coletiva, Rio de Janeiro, 2008. Disponível em: http://www.abrasco.org.br/cienciaesaudecoletiva/ artigos/artigo_int.php?id_artigo=1419. Acesso em: dez 2008.

ARÁN, M.; MURTA, D.; ZAIDHAFT, S. Transexualidade: corpo, subjetividade e saúde coletiva. Psicologia e Sociedade, Porto Alegre, v. 20, n. 1, 2008.

BARSTED, L. L. O reconhecimento dos direitos sexuais: possibilidades e limites. In: SARMENTO, D.; IKAWA, D.; PIOVESAN, F. (orgs.). Igualdade, diferença e direitos humanos. Rio de Janeiro: Lúmen Júris, 2008. p. 247-258.

BENEDETTI, M. R. Toda feita: o corpo e o gênero das travestis. Rio de Janeiro: Garamond, 2005. 
BENTO, B. A reinvenção do corpo: sexualidade e gênero na experiência transexual. Rio de Janeiro: Garamond, 2006.

BORRILLO, D. L'homophobie. Paris: Presses Universitaires de France, 2000.

BRASIL. Ministério da Saúde. Carta dos Direitos dos Usuários da Saúde. 2006. Disponível em http://portal.saude.gov.br/portal/arquivos/pdf/cartilha_integra_direitos_2006.pdf. Acesso em: nov. 2008.

. Portaria $\mathrm{n}^{\mathrm{o}}$. $1.707 / \mathrm{GM}$, de 18 de agosto de 2008. Institui, no âmbito do SUS, o Processo Transexualizador, a ser implantado nas unidades federadas, respeitadas as competências das três esferas de gestão. Diário Oficial da Uniāo, Brasília, DF, 19 de agosto de 2008(a).

. Portaria no. 2.227/GM, de 14 de outubro de 2004. Dispõe sobre a criação do Comitê Técnico Saúde para a formulação de proposta da Política Nacional de saúde da população gays, lésbicas, transgêneros e bissexuais - GLTB. Diário Oficial da Uniāo, Brasília, DF, 14 de outubro de 2004.

. Portaria n. 457/SAS, de 19 de agosto de 2008. Regulamenta o Processo Transexualizador no SUS. Diário Oficial da Uniāo, Brasília, DF, 20 de agosto de 2008(b).

BUTLER, J. Desdiagnosticar el gênero. In: . Deshacer el gênero. Barcelona: Paidós Ibérica, 2006. p. 113-148.

. Problemas de gênero. Rio de Janeiro: Civilização Brasileira, 2003.

CONSELHO FEDERAL DE MEDICINA. Resolução no $1.482 / 97$. Dispõe sobre o procedimento de transgenitalização e demais intervençōes sobre gônadas e caracteres sexuais secundários. Disponível em: http://www.portalmedico.org.br/resolucoes/cfm/1997/1482_1997.htm. Acesso em: jun. 2007.

. Resolução no 1.652/02. Dispõe sobre o procedimento de transgenitalização e revoga a Resolução 1482/1997 e demais intervenções sobre Gonadas e caracteres sexuais secundários. Disponível em: http://www.portalmedico.org.br/resolucoes/cfm/2002/1652_2002.htm. Acesso em: jun. 2007.

CONSELHO FEDERAL DE PSICOLOGIA. Resolução no 01/1999. Estabelece normas de atuação para os psicólogos em relação à questão da orientação sexual. Disponível em http:// www.crpsp.org.br/a_orien/legislacao/fr_cfp_001-99.htm. Acesso em: jun. 2007.

CONSELHO FEDERAL DE SERVIÇO SOCIAL. Resolução no 489/2006. Estabelece normas vedando condutas discriminatórias ou preconceituosas, por orientação e expressão sexual por pessoas do mesmo sexo, no exercício profissional do assistente social. Disponível em: http:// www.rits.org.br/rets/download/campanhas110707.pdf. Acesso em: jun 2007.

COSTA, A. M.; LIONÇO, T. Democracia e gestão participativa: uma estratégia para a equidade na saúde? Saúde e Sociedade, São Paulo, v. 15, n. 2, p. 47-55, p. 2006.

ERIBON, D. Reflexôes sobre a questão gay. Rio de Janeiro: Companhia de Freud, 2008. 
FRASER, N. Redistribuição, reconhecimento e participação: por uma concepção integrada da justiça. In: SARMENTO, D.; IKAWA, D.; PIOVESAN, F. (orgs.). Igualdade, diferença e direitos humanos. Rio de Janeiro: Lúmen Júris, 2008, p. 167-190.

LIONÇO, T. Bioética e sexualidade: o desafio para a superação de práticas correcionais na atenção à saúde de travestis e transexuais. Série Anis: Brasília, n. 54, 2008, p. 1-6. Disponível em: http:// www.anis.org.br/serie/visualizar_serie.cfm?IdSerie=69. Acesso em: set. 2008.

. Movimentos sociais e participação no SUS: considerações sobre a população GLBTT. Série Anis: Brasília, n. 50, 2007, p. 1-09. Disponível em: http://www.anis.org.br/serie/artigos/ sa50_lionco_glbtt.pdf. Acesso em: set. 2008.

MONTOYA, G. J. M. Aproximación bioética a las terapias reparativas. Tratamiento para El cambio de orientación homossexual. Acta Bioethica, v. 12, n. 2, p. 199-210, 2006.

MURTA, D. A psiquiatrização da transexualidade: análise dos efeitos dodiagnóstico de Transtorno de Identidade de Gênero sobre as práticas desaúde. Dissertação (Mestrado em Medicina Social) Instituto de Medicina Social, Universidade do Estado do Rio de Janeiro, Rio de Janeiro, 2007.

OLIVEIRA, N. M. Damas de paus: o jogo aberto dos travestis no espelho da mulhe. Salvador: Centro Editorial e Didático, 1994.

ORGANIZAÇÃO MUNDIAL DA SAÚDE. Classificação Estatística Internacional de Doençase Problemas relacionados à Saúde - Décima Revisão - CID 10. Disponível em: http:// www.datasus.gov.br/cid10/webhelp/cid10.htm. Acesso em: jan. 2008.

PELÚCIO, L. Toda quebrada na plástica: corporalidade e construção de Gênero entre travestis paulistas, in Campos - Revista de Antropologia Social, v. 6, n. 1 e 2, 2005. Disponível em: http:// calvados.c3sl.ufpr.br/ojs2/index.php/campos/issue/view/424. Acesso em: jul. 2007.

RAWLS, J. Justiça e democracia. São Paulo: Martins Fontes, 2002.

RIOS, R. R. Notas para o desenvolvimento de um direito democrático da sexualidade. In:

(org.). Em defesa dos direitos sexuais. Porto Alegre: Livraria do Advogado, 2007. p. 13-38.

RUSSO, J. A. Do desvio ao transtorno: a medicalização da sexualidade na nosografia psiquiátrica contemporânea, in PISCITELLI, A.; GREGORI, M. F.; CARRARA, S. (orgs.). Sexualidade e saberes: convençôes e fronteiras. Rio de Janeiro: Garamond, 2004.

SILVA, H. Travestis: entre o espelho e a rua. Rio de Janeiro: Rocco, 2007.

VENTURA, M. Transexualismo e respeito à autonomia: um estudo bioético dos aspectos jurídicos e de saúde na 'terapia de mudança de sexo'. Dissertação (Mestrado em Saúde Pública) - Escola Nacional de Saúde Pública Sérgio Arouca, Fundação Oswaldo Cruz, Rio de Janeiro, 2007. 


\section{Notas}

*As reflexōes contidas no artigo foram discutidas no Seminário Normas de Gênero e Políticas Públicas de Saúde no Brasil, realizado no Instituto de Medicina Social da UERJ em dezembro de 2008.

${ }^{1} \mathrm{O}$ levantamento dos serviços de atenção a transexuais foi realizado por meio da pesquisa "Transexualidade e Saúde: condições de acesso e cuidado integral", coordenada pela Professora Márcia Arán, do Instituto de Medicina Social da UERJ, com financiamento do CNPq e DECIT/ Ministério da Saúde. O site para acesso a informaçoes da pesquisa é http://www.ims.uerj.br/ transexualidadesaude/artigos.php.

${ }^{2} \mathrm{O}$ Conselho Federal de Medicina estabelece ascondições de viabilidade do procedimento de transgenitalização e demais intervenções sobre gônadas e caracteres sexuais secundários por meio da Resolução no 1.482 de 1997 , posteriormente revogada pela Resolução no 1.652 de 2002, que estabelece o caráter não-experimental da cirurgia do tipo neocolpovulvoplastia, estendendo sua aplicabilidade ao âmbito privado de serviços de saúde.

${ }^{3} \mathrm{O}$ projeto de decreto legislativo mencionado é de autoria do Deputado Miguel Martini e resgata o artigo 129 do Código Penal, que considera crime ofender a integridade corporal.

${ }^{4}$ A decisão do Tribunal Regional Federal da $4^{a}$ Região, cujo relator foi o Juiz Federal Roger Raupp Rios, se refere à Apelação Civil no 2001.71.00.026279-9/RS, cujo Procurador responsável foi Paulo Leivas.

${ }^{5}$ Decisão STF Ministra Ellen Gracie STA 185/DF, de 10 de dezembro de 2007.

${ }^{6}$ A noção de diversidade sexual é aqui empregada para além da referência a LGBT (Lésbicas, Gays, Bissexuais, Travestis e Transexuais), incluindo também a heterossexualidade. Assume a heterogeneidade que caracteriza a multiplicidade de formas de viver a homossexualidade, a heterossexualidade, a masculinidade e/ou a feminilidade. Não se incluem, no entanto, na afirmação da diversidade sexual, experiências sexuais que firam o ordenamento legal, tais como a pedofilia e outras formas de abuso sexual. ${ }^{7}$ O Coletivo Nacional de Transexuais vem propondo a terminologia mulheres/homens que vivenciam a transexualidade, enfatizando a necessidade de desessencializar a identidade transexual, compreendida como categoria médica. Reivindicam sua identificação às categorias mulher ou homem, afirmando que suas diferenças biológicas em relação a outras mulheres e homens não devem comprometer o reconhecimento social no gênero que expressa sua realidade subjetiva. Essa nova terminologia vem sendo incorporada a documentos governamentais, tais como na Política Nacional de Atenção Integral à Saúde da Mulher e no Plano Integrado de Enfrentamento da Feminização da Epidemia de Aids, ambos do Ministério da Saúde.

${ }^{8}$ Para um detalhamento da estratégia dos Comitês de Promoção da Equidade do Ministério da Saúde, consultar Costa e Lionço (2006), e especificamente em relação ao Comitê Técnico Saúde da População GLBT (LIONÇO, 2007). 


\section{Abstract}

Comprehensiveness and sexual diversity in the Brazilian norm in the process of health care for transsexuals: progress, dilemmas, challenges

The Brazilian norm that establishes the conditions for the health care for transsexuals, despite reflecting important achievements of this population, reveals the complexity of the advancement of sexual rights in the field of public health. This paper aims to review the advances, challenges and dilemmas in the establishment of this public health policy, discussing the ambivalence in the process of building the technical standard. It releases two parallel chains of the inclusion of the debate about transgender health care in the Health Ministry: the judicialization and the committment with the government program "Brazil without Homophobia”. It indicates the partial progress achieved by the publication of the standard, as it established exclusion areas for potential beneficiaries of the same set of health actions, specifically the transvestites, at the same time it stated the right to health care for transsexuals. The hypothesis sustained is that heteronormativity and the binary of gender work as limiting factors for the democratization of the health policy.

Key words: transsexualism; homophobia; sexual diversity; heteronormativity; transvestites. 